\title{
Challenges to future dental education
}

taking the lead. In addition there have been significant changes in the workforce and the role of the dentist. These changes will affect the future of the dental profession.

The background of developments in UK and European dental education has been discussed in an earlier article. ${ }^{1}$ With the lead in dental education moving toward a more European and even global context, it is timely to examine the challenges that will test undergraduate education for dentists of the future. There are a number of current and future developments that will have major implications for the practice of dentistry in years to come. It is imperative that undergraduate dental education equips our future dentists for these challenges. Also, that changes to dental education occur now, as it takes at least five years to train a dentist and without change our young dentists will be ill equipped for the changes that will occur in their practising lifetime.

\section{Development of the oral care team}

Dental care professionals' (DCPs') skills are increasing, with dental therapists being able to undertake simple restorations, orthodontic auxiliaries providing much orthodontic treatment, and DCPs being able to become practice owners with varying degrees of independent

'Child Dental Health, Newcastle University School of Dental Sciences, Framlington Place, Newcastle upon Tyne, NE2 4BW

Correspondence to: Dr Ross Hobson

Email:r.s.hobson@ncl.ac.uk

\section{Refereed Paper}

Accepted 22 October 2008

DOI: $10.1038 /$ sj.bdj.2009.54

${ }^{\circ}$ British Dental Journal 2009; 206: 125-126 practice that could not have been considered ten years ago.

The skill set which used to be accepted on graduation from a dental graduate will need to be broader and much, much higher. This provides challenges in trying to achieve a knowledge and understanding of new technologies, diagnosis and treatment planning. Also, a greatly increased level of technical skill will be required to undertake the advanced crown and bridge, implants, endodontics and orthodontics. The 'simple' skills set will be undertaken by the rest of the dental team.

These challenges are already being taken up within Europe. For example, in the Netherlands the combined hygiene and therapy course is a three year university degree, which in turn has acted as a pressure to increase the skills set of the newly qualified graduate to achieve a significant difference in skills between DCPs and the dental leaders of the team. They have tackled this by increasing the dental undergraduate degree from five to six years.

The dentist as the leader of an oral heath care team will need significant leadership, management and business skills, being able to act as an entrepreneur, seeking opportunities to expand their own and their team's skills and also negotiating funding contracts with the NHS and other purchasers of their services.

They also need to have a greater awareness of genomics and proteomics as these new technologies are developing rapidly and will significantly change the future of how dentistry is diagnosed and performed in years to come. Already saliva tests are available for cancer screening. It will not be long before a simple test will be indicative of cancer anywhere in the body, and as the person best skilled to undertake saliva sampling, how do we equip dentists to be able to break bad news to patients and to know the appropriate referral pathways?

The dental team can be expected to develop their wider health care role, being the one heath profession that regularly sees their patients, so skills in offering life style advice eg smoking cessation, diet advice etc will be required.

\section{Post graduation}

What happens when the student qualifies? We have seen the Modernising Medical Careers mess in medicine and the Tooke Enquiry has shown a large number of problems and issues associated with $\mathrm{F} 1 / \mathrm{F} 2$ process. In dentistry if we are to move the same model (which is very much based on our existing GDP schemes) do we have sufficient spaces for F1/F2? Sufficient trainers? Sufficient physical space in secondary care in order to provide sufficient training for our new graduates?

In addition there is the realisation that many new graduates will not follow the 'conventional' NHS vocational training pathway, with more intending to enter private practice. $^{2}$ 
The BDA is rising to this challenge already in taking leadership in providing BDA Advance, a programme for second year VT based totally in private practice, in order that students who do not wish to undertake an NHS career in primary care can learn the specific skills and needs of working in a private health care setting. It can easily be envisaged that this will extend to have a first year with dental practices investing in training of their junior colleagues for the future.

\section{Changing nature of students}

The nature of students themselves are changing. It is now accepted that ' $A$ ' levels alone are not sufficient to discriminate between the large number of applicants to the profession. Hence universities have introduced UKCAT psychometric testing in order to try and differentiate between students that, on paper, have the same abilities. This in turn has generated many challenges, as UKCAT is based on a medical model with little or no dental evidence to support its use. It will be interesting to see how UKCAT performs over the next few years and whether it acts as a reliable and valid selector for dental undergraduates which will ultimately lead to improved dentists. Currently the dental undergraduate recruitment process is at best a lottery, and at worst can be described as restrictive, many schools using various means of unproven methodology to reduce the hundreds of applicants to the number they can accommodate. If we wish to select the best students for the future of the profession dental schools will have to develop a whole new recruitment process alongside and possibly independent of 'A' levels, in order to recruit students with the necessary team working, leadership and manual dexterity for dental practice in the twenty-first century.

The second pressure from students is the increased student numbers with the undergraduate body increasing by some $25 \%$ over the past three years. Three new dental schools have opened in a very short period of time. These increased numbers have caused pressures within the existing schools to try and cope what is known as the 'bulge years' on limited chair and teaching resources both in terms of space and staffing. It is already acknowledged that this is placing an increased pressure on the existing academic workforce that has been dropping significantly in the past few years ${ }^{3}$ but hopefully new initiatives in the introduction of Walport academic clinical fellows and clinical lecturers and HEFCE new blood senior lecturers along with initiatives undertaken by the universities themselves, will make dental academia more attractive in recruiting new staff to cope with these challenges and increased numbers.

The increasing feminisation of the workforce $(60 \%$ of new dental students are female) brings challenges to workforce planning as it is accepted that the work pattern of females is different from men. In addition, there is evidence that suggests that new male graduates are tending to adapt a more feminine work pattern taking increased time off to improve their work-life balance. This raises challenges not only delivering service to the population but also to ensure appropriate representation in academia, dental associations and representative bodies.

All this is set against an increasing level of student debt with many students now graduating with over $£ 20,000$ worth of debt. Many are now starting to think, do they want an NHS career? A number are actively deciding to go straight into private practice ignoring NHS VT in order to get themselves off the perceived rat race of the NHS treadmill and help relieve themselves of their debt.

The changes in NHS funding of dentistry has implications as it restricts the ability of dentists to open up dental surgeries as and where they wish and the use of performers lists means that unless a dentist has a performers number, ie has completed VT or is on a VT programme, they are unavailable to work within the NHS. This has implications for those students who have deferred or failed their final exams in that they may be out of work for a significant number of months before being able to enrol on a
VT programme. As the universities have discharged their responsibility for training, how do these newly qualified dentists ensure they do not lose hard learned skills whilst awaiting the job lottery of NHS VT?

\section{Looking to the future}

So how well do we meet these challenges in the United Kingdom? Many schools are already rising to the challenges as has been indicated. Dental education leadership would suggest that the schools are willing and able to take the challenges on developing new curriculum training in order to achieve the necessary goals and outcomes for our new graduates.

Over the next few years we may see a significant change in how we recruit students, moving away from conventional 'A' levels and biasing more towards a UKCAT type psychometric test. For certain the undergraduate courses need to change to equip our new colleagues for the future, and not the dentistry of the past. What is certain is that the dentist of the future will be significantly different from the dentist which we know today, being a team leader, in the role of an oral physician and diagnostician using a whole armoury of tests, particularly saliva and blood to provide accurate diagnosis, counselling and therapeutics, rather than the conventional drill and fill that we have known.

If we are not equipping our new graduates with the skills to adapt and to learn novel techniques, we are underselling our dental profession for the future. This is particularly the case as it takes five years to train an undergraduate and a further five to ten years before they themselves become involved in 'politics' and change. The students we are training now are the dentists of the future; in order to influence the future, we need to undertake change now!

1. Hobson R. S. A view of European challenges in dental education. Br Dent J 2009; 206: 65-66.

2. Stewart F M, Drummond J R, Carson L, Theaker E D. Senior dental students' career intentions, work-life balance and retirement plans. Br Dent J 2007; 203: 257-263.

3. Margerison C, Morley H. Clinical academic staffing levels in UK medical and dental schools. A report by the Medical Schools Council and the Council of Heads and Deans of Dental Schools. London: Medical Schools Council and CHDDS, 2007. 